\title{
Modeling of Post-Failure Behavior of the Rock Mass and its Effect on the Stress-Deformation State in the Vicinity of a Mining Excavation
}

\author{
Halina Marczak ${ }^{1}$ \\ 1 Faculty of Mechanical Engineering, Lublin University of Technology, Lublin, e-mail: h.marczak@pollub.pl
}

\begin{abstract}
The study investigated the impact of post-failure properties of the rock mass on the stress-deformation state in the vicinity of the underground excavation and the pressure exerted on the support. An analytical solution to the problem was presented, including the creation of inelastic zones in the vicinity of the excavation: ideal-plastic zone with residual strength and plastic zone with mild decrease of rock medium strength and taking into account the dilatancy. The analysis of the obtained dependencies was carried out using geotechnical parameters characterizing the Carboniferous rock mass of a hard coal mine. The influence of the plastic zone was determined with a mild decrease in strength to the state of stress, deformation and pressure on the rock mass support. The results of the considerations were compared with the solution, which omitted the softening of the rock mass and the solution based on the model of the elastic-plastic-brittle medium. The results of the analysis broaden the knowledge on the behavior of the rock medium in the vicinity of the excavation. The obtained solution can be further developed in order to enable its practical application, especially under the conditions in which the behavior of the rock medium in the vicinity of the excavation well reflects the elastic-plastic model with a gentle drop in the strength of the rock material.
\end{abstract}

Keywords: rock mass model; modeling of excavations; strain and displacement; stress analysis; elastic-plastic model with strain-softening; Mohr-Coulomb criterion; inelastic zones.

\section{INTRODUCTION}

The mechanism of rock mass impact on the support of the underground excavation roadway has been the subject of numerous studies presented, among others in the works $[4,18,30]$. As a result, many models of computational loads of the rock mass onto the support were developed, adapted to the mining and geological conditions in the vicinity of the excavation $[2,10,12,21]$. Individual models differ with their simplifying assumptions.

The load of the support by the rock mass was assumed equal to its pressure on the support, determined according to the model of pressure creation appropriate to the conditions of the excavation location. In the case of excavations located below the critical depth [30], the deformation pressure models should be used to assess rock mass pressure.
In the deformation pressure models, it is assumed that inelastic zones arise around the excavation [8]. Two cases of inelastic zones are usually considered. In one of them, discussed, e.g. in the works $[5,15,16,26]$, it is assumed that a plastic zone is created around the excavation, and behind it the rock mass retains the characteristics of a elastic medium. The plastic zone causes action on the support of deformation pressure and static pressure. In the second case presented, among others in work [28], a cracks zone forms around the excavation, followed by a plastic and elastic zone. The cracks zone activates the action on the deformation pressure support and static pressure [6,28].

In this work, two inelastic zones were considered: a perfect-plastic zone with residual strength, adjacent to the excavation and a plastic zone behind it with mild decrease in strength (strain-softening zone). The weakening of strength in the strain-softening zone, resulting from the develop- 
ment of the rock mass's deformation, continues until the rock mass reaches the residual strength. The reports on this model can be found, among others in the works [1, 3, 13, 14, 31, 32, 35]. On the basis of the studies [13,31], the relationships showing the state of stresses, deformations and displacements of the rock mass with features of the elastic-plastic medium with strain-softening and relationship defining the rock mass pressure exerted on the support, were given. The analysis of these relationships for geomechanical conditions characterizing the Carboniferous rock mass in the Lubelski Węgiel "Bogdanka" Społka Akcyjna [Inc.] was carried out. The aim of the analysis was to determine the influence of the strainsoftening zone on the rock mass deformation and pressure on the support. The results of the considerations were compared with the solution in which the softening of the rock mass was ignored after reaching the peak strength and the solution based on the model of the elastic-plastic-brittle medium.

The results of the analysis broaden the knowledge about the behavior of the rock medium in the vicinity of the underground excavation. The obtained solution can be further developed in order to enable its practical application, especially under the conditions in which the behavior of the rock medium in the vicinity of the excavation well reflects the elastic-plastic model with strain-softening.

\section{MODEL AND ASSUMPTIONS OF EXCAVATION AND ROCK MASS}

The excavation roadway (Fig. 1), made in the rock mass with elastic-plastic properties with material softening and not exposed to the direct influence of exploitation pressure, was considered. The following designations were adopted: $a-$ radius of excavation contour, $R_{r e z}$ - radius of plastic residual zone, $R_{p}$ - radius of softening plastic zone, $p_{a}$ - support resistance to external forces, $r$ - current radius, $p_{z}$ - primary pressure in the rock mass around the excavation.

A strict solution to the distribution of stresses, strains and displacements in the rock mass around the heading was obtained after the simplification of the assumptions given below.

The rock mass has a hydrostatic state of primary stresses with a component $p_{z}$. The rock mass is considered an isotropic and homogeneous me- dium. Axisymmetric plane state of strain was assumed, independent of the state of stress along the axis of the excavation. Mass forces were omitted. A simplified stress-strain curve course for an elastic-plastic strain-softening model was taken into account (Fig. 2).

The rock mass behaves elastically linearly if it has a stress state with constituent values smaller than those that satisfy the strength condition. In the research, a linear Mohr-Coulomb failure criterion $[17,22,25]$ was assumed, expressed by the equation (positive compressive stresses):

$$
\sigma_{1}=K^{0} \sigma_{3}+R_{c}^{0}
$$

where: $\sigma_{1} \mathrm{i} \sigma_{3}$ are the main stresses, the highest and the lowest, respectively, acting in the plane of the excavation, $K^{0}=\left(1+\sin \varphi^{0}\right) /\left(1-\sin \varphi^{0}\right)$,

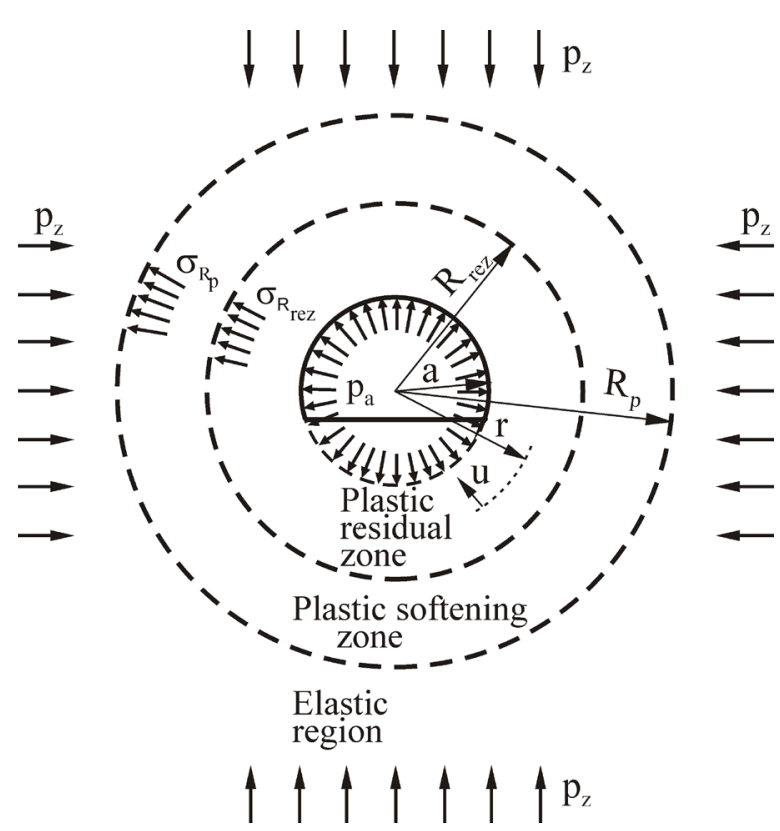

Fig. 1. Model of excavation and zones in the rock mass medium

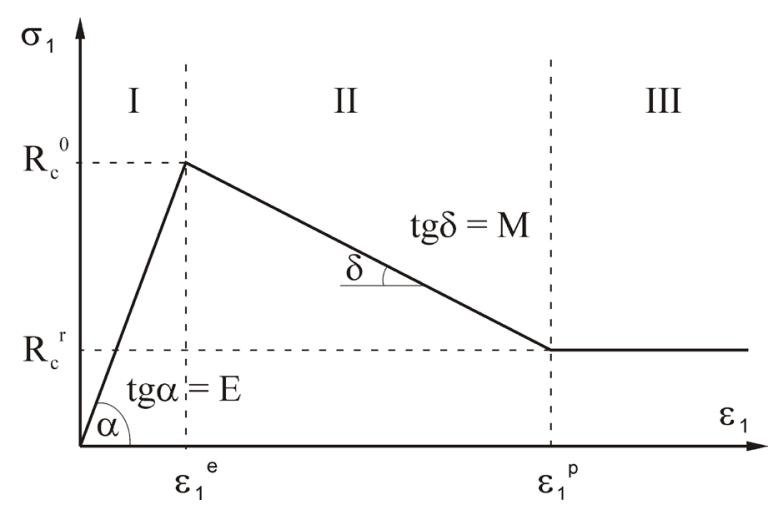

Fig. 2. Idealized course of stress-strain curve for the elastic-plastic model with softening 
$R_{c}^{0}$ is uniaxial compressive strength of rock mass, $R_{c}^{0}=\left(2 c^{0} \cos \varphi^{0}\right) /\left(1-\sin \varphi^{0}\right)$, $c^{0}$ is the cohesion of the rock mass, $\varphi^{0}$ is the angle of internal friction of the rock mass.

After reaching the peak stress (Eq. 1) in the rock mass around the excavation, the deformation process begins, accompanied by the decreasing strength of the rock medium [22, 30, 34]. The weakening of the rock structure strength occurs as a result of a decrease in cohesion [31]. It was assumed that the cohesion of the medium decreases linearly, with the increase of plastic deformation, from the value of cohesion corresponding to the compressive strength to the cohesion of the residual medium. The impact of the change in the angle of internal friction on the decline in the strength of the rock mass was neglected. The rock material with residual strength can continue to deform at a constant stress value.

The phases of deformation of the rock medium illustrate successive parts of the curve in Figure 2. In the elastic phase (I), the graph of the dependence of strain on deformation is a straight line with an angle of inclination depending on the value of the Young's modulus $(E)$ of the rock medium. In the plastic phase with softening $(I I)$, the deformation meets the condition, $\left(\varepsilon_{1}{ }^{e}\right)$ ${ }_{r=R p} \leq \varepsilon_{1}<\left(\varepsilon_{1}^{p}\right)_{r=\text { Rrez }}$, and the strength of the rock medium decreases to the residual value $\left(R_{c}^{r}\right)$. In the phase with residual strength, $\varepsilon_{1} \geq\left(\varepsilon_{1}^{p}\right)_{r=\text { Rrez }}$, occurs. The location of the considered deformation phases (zones) around the excavation is marked in Figure 1.

The problem is considered in the polar coordinate system, in which, $\sigma_{r}, \sigma_{t}$ are respectively the radial and circumferential stress in the rock mass around the excavation, $\varepsilon_{r}$ is the radial strain, $\varepsilon_{t}$ is the circumferential strain. In the symbols of stresses and strains in the residual plastic zone, in the plastic zone with softening and in the elastic zone, the "rez", " $p$ ", "e" superscripts were used, respectively.

The strength properties of the rock medium in the elastic phase are described in Eq. (1) which, after taking into account $\sigma_{1}=\sigma_{t}$ and $\sigma_{3}=\sigma_{r}$, has the form

$$
\sigma_{t}=K^{0} \sigma_{r}+R_{c}^{0}
$$

The strength condition (2) applies to the radius $(r)$ at the boundary of the elastic and plastic zone around the excavation. In the plastic phase with softening, the relationship (2) takes the form of

$$
\sigma_{t}^{p}=K^{0} \sigma_{r}^{p}+R_{c}^{p}
$$

where $R_{c}^{p}$ is the uniaxial compressive strength of the rock mass within the plastic zone with softening, which is determined by the formula:

$$
\left.R_{c}^{p}=R_{c}^{0}-M \mid \varepsilon_{t}^{p}-\left(\varepsilon_{t}^{e}\right)_{r=R_{p}}\right\rfloor
$$

where $M$ is the tangent of the slope of the curve $\sigma-\varepsilon$ within the plastic zone with softening (Fig. 2).

In the residual area, the Coulomb-Mohr strength condition can be presented as:

$$
\sigma_{t}^{r e z}=K^{0} \sigma_{r}^{r e z}+R_{c}^{r}
$$

where $R_{c}^{r}$ is the uniaxial compressive strenght of the rock medium in the residual zone.

In the plastic zone with softening and in the plastic residual zone, dilatancy of the rock medium is taken into account. The change in the volume of rock material in the plastic zone with softening is characterized by the dilatancy parameter $\left(\beta_{1}\right)$, which is related to the dilatancy angle $(\psi)$ according to the relationship $[29,33]$ :

$$
\beta_{1}=\frac{1+\sin \psi}{1-\sin \psi}
$$

For $\psi=0$ there is no change in volume in the rock medium, for $\psi>0$ the rock material in the non-elastic zone increases the volume. The angle of dilatancy of the rock mass $(\psi)$ is determined using the results of three-axis tests [31]. On the basis of research $[9,14,29,31]$ and the non-associated law of plastic flow, the relationship between radial and circumferential strain of the rock mass in the plastic zone with strain-softening can be presented as:

$$
\Delta \varepsilon_{r}^{p}+\beta_{1} \Delta \varepsilon_{t}^{p}=0
$$

where $\Delta \varepsilon_{r}^{p}, \Delta \varepsilon_{t}^{p}$ is the an increase in respectively radial and circumferential strain in the plastic zone with softening.

In the plastic residual zone, the relationship between strains is:

$$
\Delta \varepsilon_{r}^{r e z}+\beta_{2} \Delta \varepsilon_{t}^{r e z}=0
$$

where $\Delta \varepsilon_{r}^{r e z}, \Delta \varepsilon_{t}^{r e z}$ is the an increase in respectively radial and circumferential strain in the residual zone. The dilatancy parameter in the residual zone $\left(\beta_{2}\right)$ is determined with the formula [31]:

$$
\beta_{2}=1+\Phi
$$

where $\Phi$ takes values from the range $0.3-0.5$. 
The $\beta_{1}$ and $\beta_{2}$ parameters influence the course of the curve describing deformation properties of the rock medium (Fig. 3).

\section{THE INFLUENCE OF INELASTIC ZONES AROUND THE EXCAVATION ON THE STRESS-STRAIN STATE AND ROCK MASS PRESSURE ONTO THE SUPPORT}

The considered elastic-plastic rock mass can be, depending on the level of effort, in the elastic state, plastic with strain-softening or in the residual plastic state. The location of the elastic zone and inelastic zones in the surroundings of the excavation is marked in Figure 1.

The radial stress at the boundary of the elastic and plastic area $\left(\sigma_{R p}\right)$ takes the value specified by the formula:

$$
\sigma_{R_{p}}=\frac{2 p_{z}-R_{c}^{0}}{1+K^{0}}
$$

The value $\sigma_{R p}$ means the lowest radial stress necessary for maintaining the rock mass in the elastic state. Thus, with the support load capacity at least equal to $\sigma_{R p}$ the rock mass will remain in the elastic state. Otherwise, inelastic zones may form around the excavation.

The state of stress in the elastic area $\left(r \geq R_{p}\right.$, Fig. 1) is determined with Eqs. (11-12):

$$
\begin{gathered}
\sigma_{r}^{e}=p_{z}\left(1-\frac{R_{p}^{2}}{r^{2}}\right)+\sigma_{R_{p}} \frac{R_{p}^{2}}{r^{2}} \\
\sigma_{t}^{e}=p_{z}\left(1+\frac{R_{p}^{2}}{r^{2}}\right)-\sigma_{R_{p}} \frac{R_{p}^{2}}{r^{2}}
\end{gathered}
$$

Elastic strain is the result of the increase in stress $\left(\Delta \sigma_{r}^{e}, \Delta \sigma_{t}^{e}\right)$ as a result of the excavation:

$$
\begin{gathered}
\Delta \sigma_{r}^{e}=\sigma_{r}^{e}-p_{z} \\
\Delta \sigma_{t}^{e}=\sigma_{t}^{e}-p_{z}
\end{gathered}
$$

Strains in the elastic area (for a plane state of strain) are expressed by means of the formulas [11[:

$$
\begin{gathered}
\varepsilon_{r}{ }^{e}=-\frac{1+v}{E}\left(p_{z}-\sigma_{R_{p}}\right) \frac{R_{p}^{2}}{r^{2}} \\
\varepsilon_{t}{ }^{e}=-\varepsilon_{r}^{e}
\end{gathered}
$$

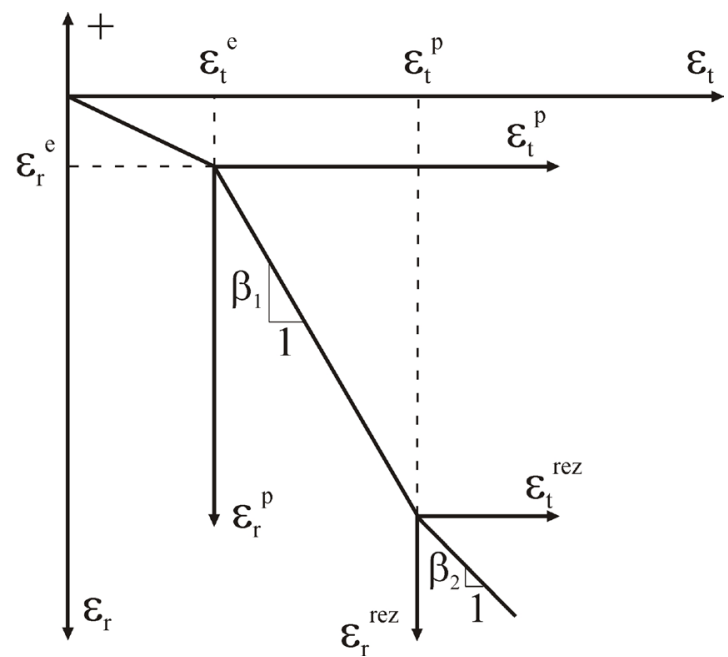

Fig. 3. Relationship between the strain of rock medium and dilatancy parameter

From the geometrical equation, $\varepsilon_{t}^{e}=u^{e} / r$ [33], it follows that the radial displacement of a rock mass in the elastic area $\left(u^{e}\right)$ is equal to

$$
u^{e}=\frac{1+v}{E}\left(p_{z}-\sigma_{R_{p}}\right) \frac{R_{p}^{2}}{r}
$$

In the plastic zone with softening (Fig. 1, $\left.R_{r e z} \leq r<R_{p}\right)$, the strain can be expressed as:

$$
\begin{aligned}
& \varepsilon_{r}^{p}=\left(\varepsilon_{r}^{e}\right)_{r=R_{p}}+\Delta \varepsilon_{r}^{p} \\
& \varepsilon_{t}^{p}=\left(\varepsilon_{t}^{e}\right)_{r=R_{p}}+\Delta \varepsilon_{t}^{p}
\end{aligned}
$$

After substituting to Eq. (18) for $\Delta \varepsilon_{r}^{p}$ the expression resulting from Eq. (7), to Eqs. (18-19), respectively, the formulas (15) and (16) and geometrical equations, $\varepsilon_{t}^{p}=u^{p} / r$ and $\varepsilon_{r}^{p}=d u^{p} / d r$ [33], then after the appropriate transformations, the equation determining the field of displacements in the plastic zone with softening was obtained $\left(u^{p}\right)$ :

$$
\frac{d u^{p}}{d r}+\beta_{1} \frac{u^{p}}{r}=\frac{1+v}{E}\left(p_{z}-\sigma_{R_{p}}\right)\left(\beta_{1}-1\right)
$$

On the basis of the solution of Eq. (20), strains in the plastic zone with softening can be calculated as follows:

$$
\begin{aligned}
& \varepsilon_{t}^{p}=\frac{u^{p}}{r}=\frac{(1+v)\left(p_{z}-\sigma_{R_{p}}\right)}{E}\left[\frac{\beta_{1}-1}{\beta_{1}+1}+\frac{2}{\beta_{1}+1}\left(\frac{R_{p}}{r}\right)^{\beta_{1}+1}\right] \\
& \varepsilon_{r}^{p}=\frac{d u^{p}}{d r}=\frac{(1+v)\left(p_{z}-\sigma_{R_{p}}\right)}{E}\left[\frac{\beta_{1}-1}{\beta_{1}+1}-\frac{2 \beta_{1}}{\beta_{1}+1}\left(\frac{R_{p}}{r}\right)^{\beta_{1}+1}\right]
\end{aligned}
$$

Substituting to the equilibrium equation (23) [14]:

$$
\frac{d \sigma_{r}}{d r}+\frac{\sigma_{r}-\sigma_{t}}{r}=0
$$


the expression (3) (after taking into account Eqs. (4), (15-16) and (19)) and then, by integrating the transformed Eq. (23) with the boundary condition, $\left(\sigma_{r}^{p}\right)_{r=R p}=\sigma_{R p}$, the relationship (Eq. 24) describing the value of radial stress in the plastic zone with softening was obtained

$$
\begin{aligned}
& \sigma_{r}^{p}=\frac{2}{K^{0}+1}\left[p_{z}+\frac{R_{c}^{0}}{K^{0}-1}+\frac{\left(K^{0}+1\right) M A}{\left(K^{0}-1\right)\left(K^{0}+\beta_{1}\right)}\right]\left(\frac{r}{R_{p}}\right)^{K^{0}-1} \\
& -\frac{1}{K^{0}-1}\left(\frac{2 M A}{1+\beta_{1}}+R_{c}^{0}\right)+\frac{2 M A}{\left(K^{0}+\beta_{1}\right)\left(1+\beta_{1}\right)}\left(\frac{R_{p}}{r}\right)^{1+\beta_{1}}
\end{aligned}
$$

where: $A=(1+v)\left(p_{z}-\sigma_{R_{p}}\right) / E$.

In the plastic residual zone (Fig. $1, a \leq r<R_{r e z}$ ), of the stress state equation can be obtained by solving the equation of equilibrium (23), in which $\sigma_{t}$ is substituted for $\sigma_{t}^{r e z}$ according to it Eq. (5), and $\sigma_{r}$ by $\sigma_{r}^{r e z}$. The obtained solution $\sigma_{r}^{r e z}$ and $\sigma_{t}^{r e z}$ with the boundary condition, $\left(\sigma_{r}^{r e z}\right)_{r=a}=p_{a}$, has the form:

$$
\begin{array}{r}
\sigma_{r}^{r e z}=r^{K^{0}-1}\left(p_{a}+\frac{R_{c}^{r}}{K^{0}-1}\right) / a^{K^{0}-1}-\frac{R_{c}^{r}}{K^{0}-1} \\
\sigma_{t}^{r e z}=K^{0} r^{K^{0}-1}\left(p_{a}+\frac{R_{c}^{r}}{K^{0}-1}\right) / a^{K^{0}-1}-\frac{R_{c}^{r}}{K^{0}-1}
\end{array}
$$

In the residual area, the total strains, respectively radial $\left(\varepsilon_{r}^{r e z}\right)$ and circumferential $\left(\varepsilon_{t}^{r e z}\right)$ are the sum of the strains at the border with the plastic zone with softening $\left(\left(\varepsilon_{r}^{p}\right)_{r=\text { Rrez }},\left(\varepsilon_{t}^{p}\right)_{r=\text { Rrez }}\right)$ and their increment in the residual zone $\left(\Delta \varepsilon_{r}^{\text {rez }}\right.$ and $\left.\Delta \varepsilon_{t}^{\text {rez }}\right)$ :

$$
\begin{aligned}
& \varepsilon_{r}^{r e z}=\left(\varepsilon_{r}^{p}\right)_{r=R_{r c z}}+\Delta \varepsilon_{r}^{r e z} \\
& \varepsilon_{t}^{r e z}=\left(\varepsilon_{t}^{p}\right)_{r=R_{r e z}}+\Delta \varepsilon_{t}^{r e z}
\end{aligned}
$$

Using the formulas (8), (21-22) and geometric equations $\left(\varepsilon_{r}^{r e z}=d u^{r e z} / d r\right.$ and $\left.\varepsilon_{t}^{r e z}=u^{r e z} / r\right)$, the system of equations (27-28) can be transformed into the following form:

$$
\begin{aligned}
\frac{d u^{r e z}}{d r} & +\beta_{2} \frac{u^{r e z}}{r}=A\left[\frac{\beta_{1}-1}{\beta_{1}+1}-\frac{2 \beta_{1}}{\beta_{1}+1}\left(\frac{R_{p}}{R_{r e z}}\right)^{\beta_{1}+1}\right]+ \\
& +A \beta_{2}\left[\frac{\beta_{1}-1}{\beta_{1}+1}+\frac{2}{\beta_{1}+1}\left(\frac{R_{p}}{R_{r e z}}\right)^{\beta_{1}+1}\right]
\end{aligned}
$$

where $u^{r e z}$ is the radial displacement of the rock mass in the residual area.

The solution of the equation (29), fulfilling the condition, $\left(u^{\text {rez }}\right)_{r=\text { Rrez }}=\left(u^{p}\right)_{r=\text { Rrez }}$, is presented by the formula:

$$
\begin{gathered}
u^{r e z}=2 \operatorname{Ar}\left\{\left[\frac{\beta_{2}-\beta_{1}}{\left(1+\beta_{1}\right)\left(1+\beta_{2}\right)}+\frac{1}{1+\beta_{2}}\left(\frac{R_{r e z}}{r}\right)^{1+\beta_{2}}\right] .\right. \\
\left.\cdot\left(\frac{R_{p}}{R_{r e z}}\right)^{1+\beta_{1}}+\frac{\beta_{1}-1}{2\left(1+\beta_{1}\right)}\right\}
\end{gathered}
$$

An important aspect of the analysis is the determination of the stress value at the boundary of the residual plastic zone and plastic zone with softening $\left(\sigma_{\text {Rrez }}\right)$ as a function of only the geomechanical parameters of the rock mass. When the maximum (for $r=R_{r e z}$ ) circumferential strain $\left(\varepsilon_{t}^{p}\right)$ according to Eq. (21) exceeds the peak deformation in the rock mass at compression $\left(\varepsilon^{g}\right)$, it goes into a residual state. Eq. (24) fulfilling the condition, $\left(\sigma_{r}^{p}\right)_{r=\text { Rrez }}=\sigma_{\text {Rrez }}$, after replacing the quotient $\left(R_{r e z} / R_{p}\right)$ with the expression designated from Eq. (21) (after considering, $r=R_{r e z}$ and $\varepsilon_{t}{ }^{p}=\varepsilon^{g}$ ), can be presented in the form:

$$
\begin{gathered}
\sigma_{R_{r e z}}=\frac{1}{K^{0}+1}\left[p_{z}+\frac{R_{c}^{0}}{K^{0}-1}+\frac{\left(K^{0}+1\right) M A}{\left(K^{0}-1\right)\left(K^{0}+\beta_{1}\right)}\right] . \\
\cdot\left[\left(\beta_{1}+1\right) \frac{\varepsilon^{g}}{A}-\left(\beta_{1}-1\right)\right]^{\frac{1-K^{0}}{\beta_{1}+1}}-\frac{1}{K^{0}-1}\left(\frac{2 M A}{1+\beta_{1}}+R_{c}^{0}\right)+ \\
+\frac{M A}{\left(K^{0}+\beta_{1}\right)\left(1+\beta_{1}\right)}\left[\left(\beta_{1}+1\right) \frac{\varepsilon^{g}}{A}-\left(\beta_{1}-1\right)\right]
\end{gathered}
$$

The value $\sigma_{\text {Rrez }}$ should be interpreted as the minimum value of radial stress necessary to prevent the rock mass from turning into a residual state. The radius of the plastic zone with softening $\left(R_{p}\right)$ can be determined from the formula:

$$
R_{p}=R_{r e z}\left[1+\frac{\left(1+h_{1}\right)\left(R_{c}^{0}-R_{c}^{r}\right)}{2 M A}\right]^{\frac{1}{1+h_{1}}}
$$

Compound (31) was obtained on the basis of Eq. (4). The determination of the radius of the residual plastic zone $\left(R_{\text {rez }}\right)$ involves the solution of the system of two equations. One of them is Eq. (32), and the other results from the assumption of equality of radial stresses at the border of the plastic zone with softening and residual $\left.\left(\left(\sigma_{r}^{p}\right)_{r=\text { Rrez }}=\left(\sigma_{r}^{\text {rez }}\right)_{r=\text { Rrez }}\right)\right)$.

The rock material within the residual plastic zone may cause an effect on the static pressure support $\left(q_{z}\right)$ with a value determined according to the formula:

$$
\left.q_{z}=\gamma\left(R_{r e z}-a\right)\right)
$$

where $\gamma$ is the volume weight of the rock mass. 
In the case when no residual plastic zone is formed in the rock mass around the excavation, then the rock medium in the post-elastic stage is considered as a plastic medium with softening. Then, the radius of the plastic zone is determined from the formula (24) (after taking, $\sigma_{r}^{p}=p_{a}$ and $r=a$ ), and the static pressure of the rock mass onto the support on the basis of the following relationship:

$$
\left.q_{z}=\gamma\left(R_{p}-a\right)\right)
$$

\section{ASSESSMENT OF THE IMPACT OF THE ADOPTED CONCEPT OF ROCK MASS MODELING ON STRESSES AND STRAINS IN THE VICINITY OF THE EXCAVATION}

The values of calculation parameters are presented in Table 1. They belong to the set of values describing the rock mass and mining conditions in the vicinity of the excavations in the Lubelski Węgiel „Bogdanka” S.A. mine.

Figure 4 shows the effect of considering the softening of the rock mass in the post-failure phase on the course of stresses and the radius of the plastic zone around the excavation. The circumferential stresses reach the maximum value at the boundary of the elastic and plastic zones. The maximum value of circumferential stress $\left(\sigma_{t}\right)$ corresponds to the horizontal axis radius of the plastic zone $\left(R_{p}\right)$, which in the case of omitting the weak- ening of the rock medium (option $I$ ) is $R_{p}=4.74 \mathrm{~m}$ $\left(p_{a}=0.1 \mathrm{MPa}\right), R_{p}=4.7 \mathrm{~m}\left(p_{a}=0.224 \mathrm{MPa}\right)$. Taking into account the softening of the rock medium in the plastic zone affects the increase of the radius of this zone, $R_{p}=5.67 \mathrm{~m}\left(p_{a}=0.1 \mathrm{MPa}\right)$, which is an increase of approx. $20 \%$, compared to the previous variant. The use of a support with loadbearing capacity $p_{a}=0.224 \mathrm{MPa}$ causes that in the analysis with softening the radius of the plastic zone is $R_{p}=5.35 \mathrm{~m}$ (an increase of approx. 14\%, compared to option $I$ ).

The more the location of the maximum circumferential stress is shifted towards the interior of the mass, the larger the area of the plastic zone $\left(R_{p}\right)$ in the vicinity of the excavation and, at the same time, the larger area of the rock medium with reduced bearing capacity.

Figure 5 presents a comparison of the calculation results based on the elastic-plastic model with softening and according to the rock mass model exhibiting the features of a three-phase elastic-plastic-brittle medium. The relationship between stress and strain for the tested threephase medium is illustrated in Figure 6.

The condition of the Coulomb-Mohr limit state for a three-phase center model at the boundary of the elastic and plastic zone is defined by means of formula (2). The analysis assumes that in the plastic phase the compressive strength of the rock mass decreases to the value of $R_{c}=0.5 R_{c}{ }^{0}$. This is reflected in the condition of the limit state for this phase:

Table 1. Values of calculation parameters

\begin{tabular}{|c|c|c|c|c|c|}
\hline \multicolumn{2}{|r|}{ Parameter } & Symbol & Unit & Value & Source \\
\hline \multirow{14}{*}{ Rock mass } & Poisson's ratio & $v$ & - & 0.215 & [23] \\
\hline & Rock mass rating & $R M R$ & - & 43 & [23] \\
\hline & Elasticity coefficient & $E$ & GPa & 6.683 & $E=10^{\frac{R M R-10}{40}}[27]$ \\
\hline & Angle of internal friction & $\varphi^{0}$ & $\operatorname{deg}$ & 36 & [7] \\
\hline & Uniaxial compressive strength & $R_{c}^{0}$ & $\mathrm{MPa}$ & 16.33 & [7] \\
\hline & $\begin{array}{l}\text { Uniaxial compressive strenght in the } \\
\text { residual zone }\end{array}$ & $R_{c}^{r}$ & $\mathrm{MPa}$ & 1.633 & adopted value \\
\hline & Cohesion & $c^{0}$ & $\mathrm{MPa}$ & 4.16 & $\begin{array}{c}\text { calculated, } \\
c^{0}=R_{c}^{0}\left(1-\sin \varphi^{0}\right) /\left(2 \cos \varphi^{0}\right)\end{array}$ \\
\hline & Residual cohesion & $C^{r}$ & $\mathrm{MPa}$ & 0.416 & adopted value \\
\hline & Volumetric weight & V & $\mathrm{MN} / \mathrm{m}^{3}$ & 0.026 & [7] \\
\hline & Softening module & $M$ & $\mathrm{MPa}$ & 3843 & calculated, Eq. (4) \\
\hline & Peak longitudinal compressive strain & $\varepsilon^{g}$ & - & 0.007 & adopted value \\
\hline & Angle dilatancy & $\psi$ & deg & 10 & adopted value \\
\hline & \multirow{2}{*}{ Dilatancy parameter } & $\beta_{1}$ & - & 1.42 & calculated, Eq. (6) \\
\hline & & $\beta_{2}$ & - & 1.4 & [31] \\
\hline \multirow{2}{*}{$\begin{array}{l}\text { Mining } \\
\text { conditions }\end{array}$} & Excavation depth & $H$ & $\mathrm{~m}$ & 922.7 & [7] \\
\hline & Radius of excavation contour & a & $\mathrm{m}$ & 3.65 & [7] \\
\hline
\end{tabular}




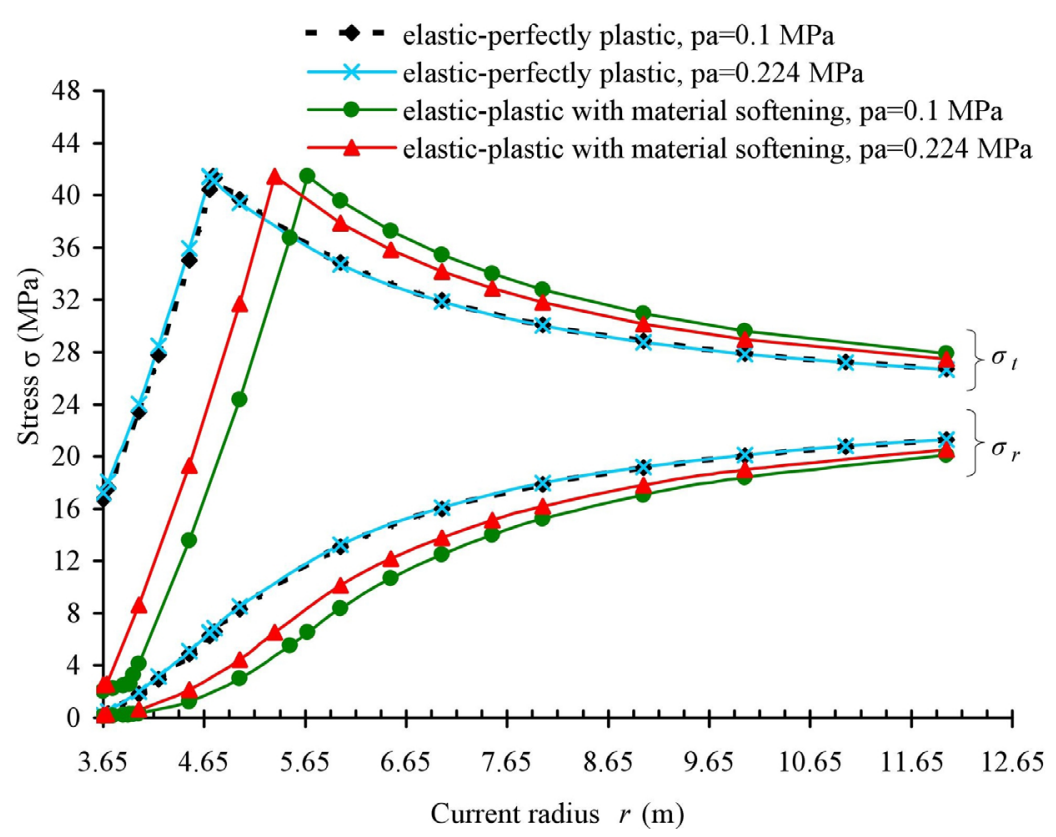

Fig. 4. The effect of considering the softening of the rock medium in the post-failure stage on the course of stresses in the vicinity of the excavation

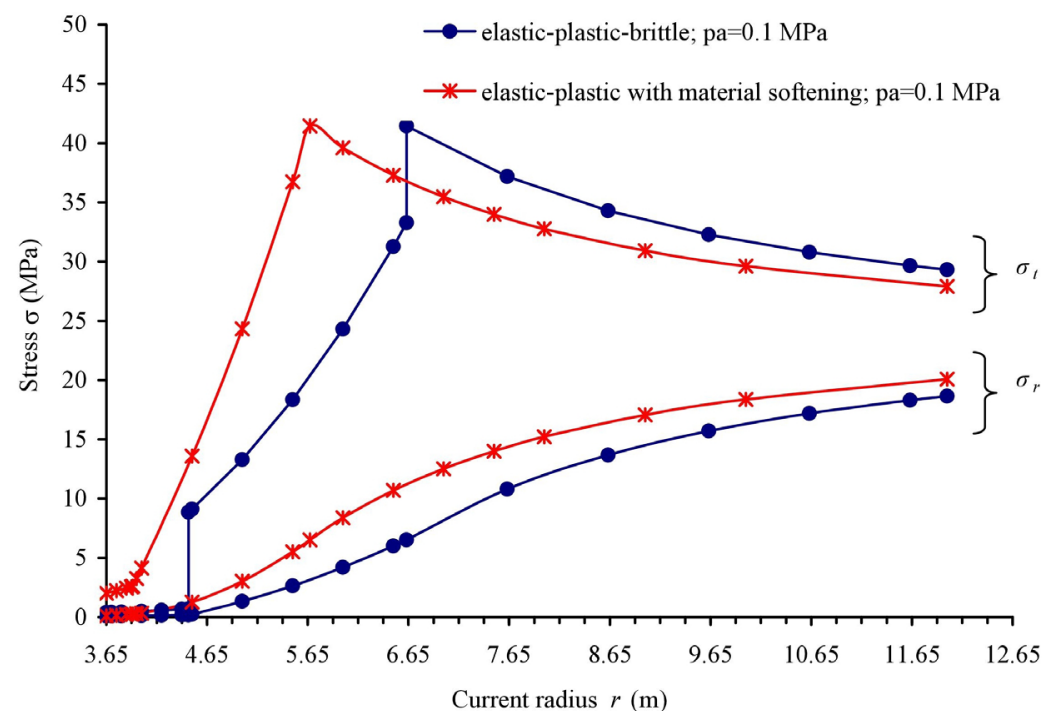

Fig. 5. The effect of applying a model of elastic-plastic medium with softening and elastic-plastic-brittle in the analysis of stresses around the excavation

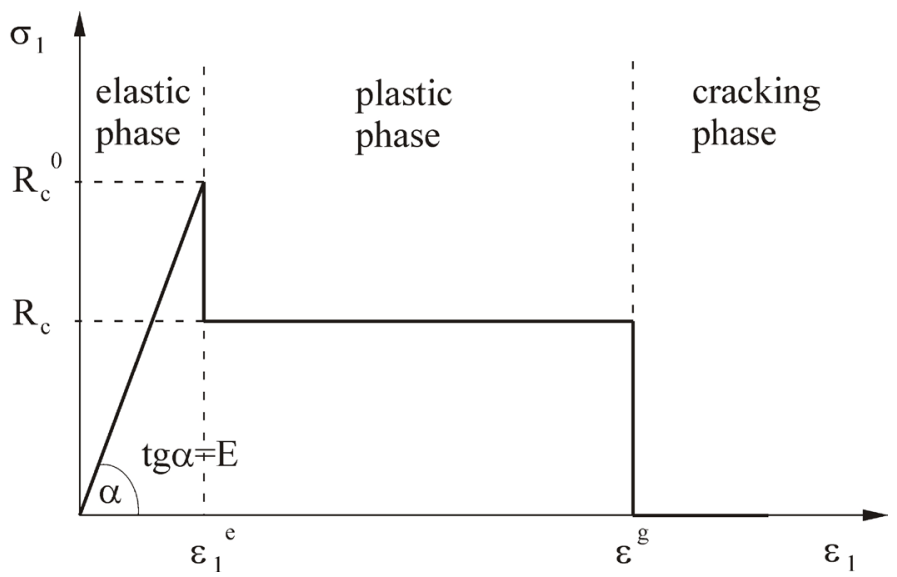

Fig. 6. Relationship between stress and strain for the elastic-plastic-brittle medium 


$$
\sigma_{t}=K^{0} \sigma_{r}+R_{c}
$$

In the phase of a cracked three-phase medium, the strength properties are described by the equation:

$$
\sigma_{t}=K^{0} \sigma_{r}
$$

In the considerations with the use of the elastic-plastic-brittle model, the dilatancy of the rock medium in the post-elastic stage was not considered. Other assumptions and input data for the calculations using this model were adopted at the same values as in the analysis using the elasticplastic model with softening.

Figure 5 shows that the radius of the plastic zone in the three-phase elastic-plastic-brittle medium is $R_{p}=6.63 \mathrm{~m}$ (for $p_{a}=0.1 \mathrm{MPa}$ ), and in the elastic-plastic medium with softening $R_{p}=4.74 \mathrm{~m}$ (for $\left.p_{a}=0.1 \mathrm{MPa}\right)$. The second of these values $\left(R_{p}\right)$ is approx. $28.5 \%$ lower than the first one.

The results of the calculation of the range of the plastic zone with softening and residual plastic zone for the elastic-plastic medium with softening as well as the plastic zone and cracks for the elastic-plastic-brittle medium model depending on the support resistance $\left(p_{a}\right)$ are shown in Figure 7. For the elastic-plastic medium model with softening, the growth of $p_{a}$ from 0.1 to 0.224 $\mathrm{MPa}$ decreases the radius of the plastic zone from 5.67 to $5.35 \mathrm{~m}$ (by approx. 5.6\%). At $p_{a} \geq 0.247$ $\mathrm{MPa}$ no residual zone is formed. For a model of elastic-plastic-brittle medium, the increase of $p_{a}$ from 0.01 to $0.1 \mathrm{MPa}$ results in reduction in the radius of the plastic zone from 14.87 to $6.63 \mathrm{~m}$ (by approx. 55\%). At a value of $p_{a}$ no lower than $0.178 \mathrm{MPa}$ no cracks zone is formed.

The effect of the impact of support load capacity on reducing the radius of inelastic zones is more significant in the rock mass with the features of the elastic-plastic-brittle medium, than for the elastic-plastic medium with softening. When $p_{a}$ grows from 0.1 to $0.2 \mathrm{MPa}$, the radius of the plastic zone for these centers decreases by approx. $18.5 \%$ and $4.7 \%$, respectively.

Figure 8 shows the effect of rock medium dilatancy on radial displacement in the vicinity of the excavation. As a result of the increase of the dilatancy angle $(\psi)$ from 0 to $30 \mathrm{deg}$, the radial displacement of the contour of the excavation increases from 25 to $52.6 \mathrm{~mm}$ (by 105\%; 2.1 times). The calculations indicate that dilatancy has the greatest impact on the radial displacement within the residual plastic zone.

The influence of the support load capacity values (in the range from 0 to $0.6 \mathrm{MPa}$ ) and the dilatancy angle (in the range from 0 to $30 \mathrm{deg}$ ) on the radial displacement of the excavation contour is shown in Figure 9a. Increasing the value of the support load capacity is accompanied by a decrease in the displacement value. The influence of the dilatancy angle on this dependence decreases with the increase of the support load capacity. Increasing the value of the dilatancy angle is accompanied by a growth in the displacement value.

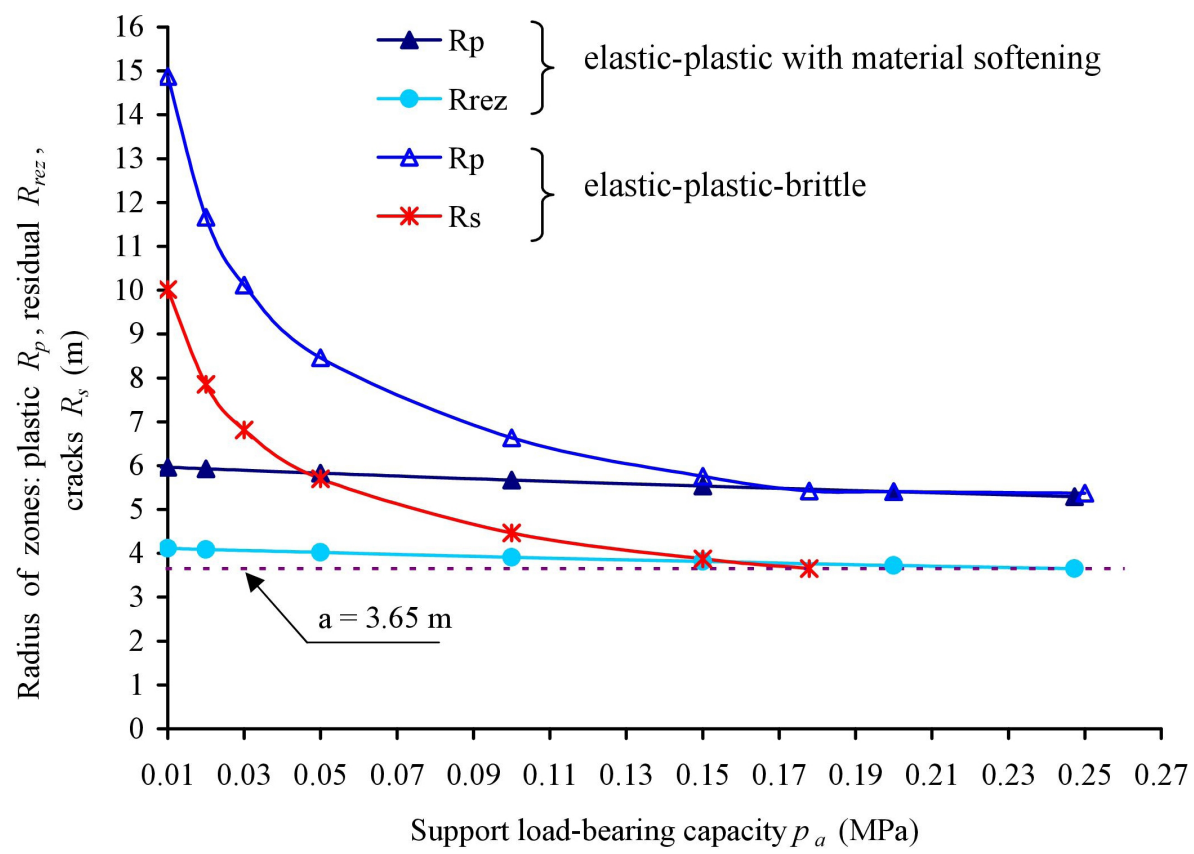

Fig. 7. Changing the radius of inelastic zones around the excavation depending on the support load capacity 


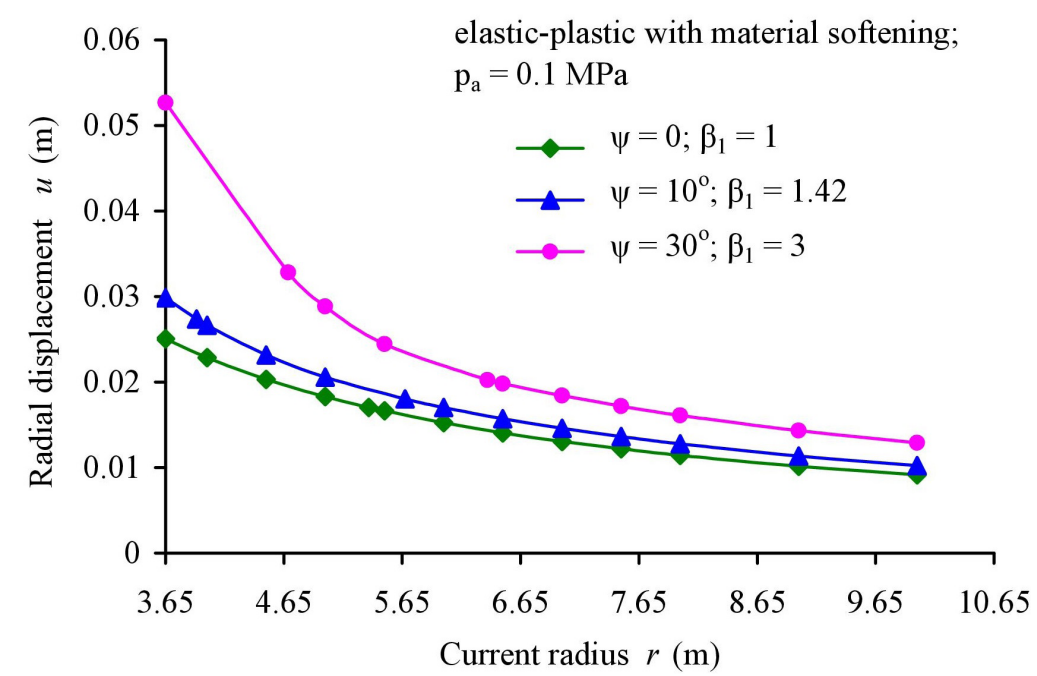

Fig. 8. The course of changes in the displacement of the radial rock mass around the excavation, taking into account the influence of dilatancy

The shaping of the displacement of the radial contour of the excavation in the elastic-plasticbrittle rock medium depending on the value of the support load capacity is illustrated in Figure 9b. The $\delta$ parameter expresses the degree of increasing the volume of rocks in the brittle zone. Greater support strength inhibits the deformation of the rock medium. The displacement of the contour of the excavation at $\delta=0$ assumes, for the same support load capacity, higher values compared to the solution for the elastic-plastic medium with weakening (for the angle of dilatancy $\psi=0$ ). The same conclusion can be formulated on the basis of a comparison of the curve for $\delta=0$ (Fig. 9b) with the curve for the dilatation angle $\psi=30 \mathrm{deg}$ (Fig. 9a), but only up to the support load capacity value approx. $0.06 \mathrm{MPa}$. In addition to this range, for a given support load capacity value, displacement of the contour of the excavation for

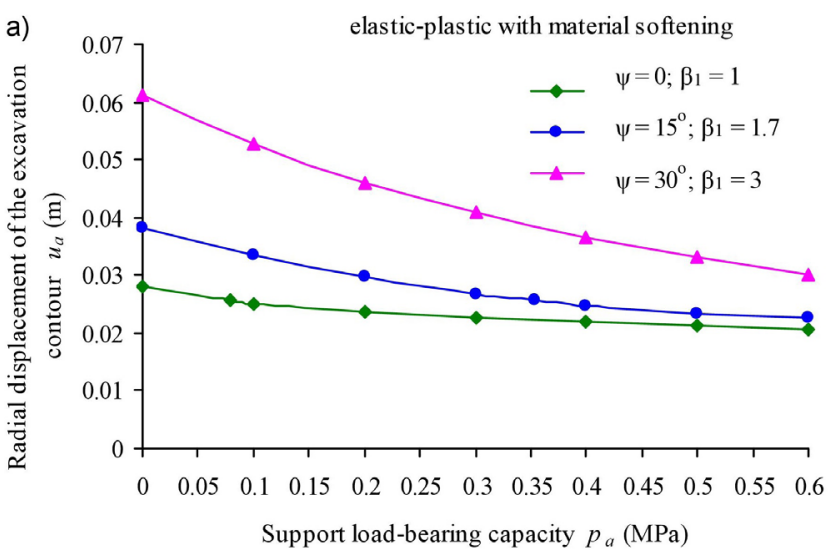

Fig. 9. The influence of the support load capacity value on displacement of the excavation contour; a) elastic-plastic with material softening, b) elastic-plastic-brittle

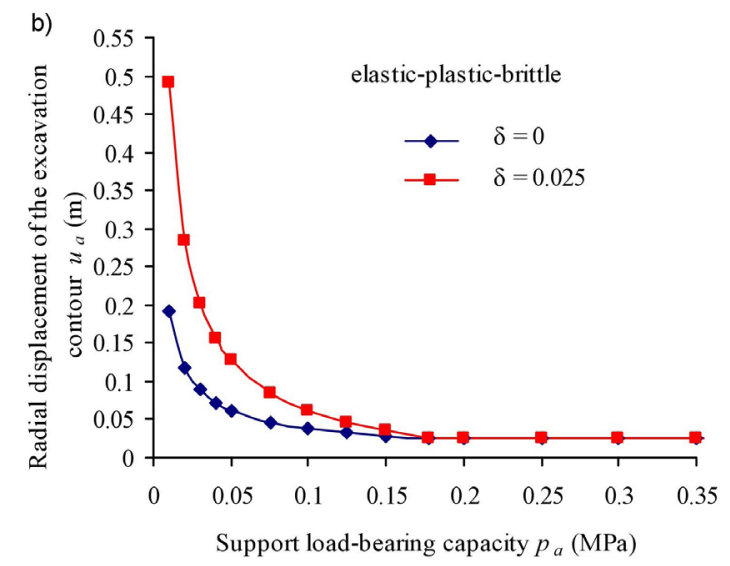

a model of elastic-plastic medium with softening is slightly higher in relation to the model of the elastic-plastic-brittle medium.

The results of calculations of the static pressure of the rock mass onto the support, depending on the support's resistance, are shown in Figure 10.

They indicate the high impact of support load capacity to the pressure exerted on the support by the rock massif with the features of the elasticplastic-brittle medium. The rate of pressure drop with the increase in the support load capacity value is the highest in the range of support load capacity values from 0 to approx. $0.05 \mathrm{MPa}$. At a value of $p_{a} \geq 0.178 \mathrm{MPa}$, no brittle zone is formed. The results for the elastic-plastic rock mass with softening and elastic-perfectly plastic show that the static pressure decreases mildly non-linearly with the increase in support load capacity. At a value of $p_{a} \geq$ $0.247 \mathrm{MPa}$, a residual plastic zone is not formed. 


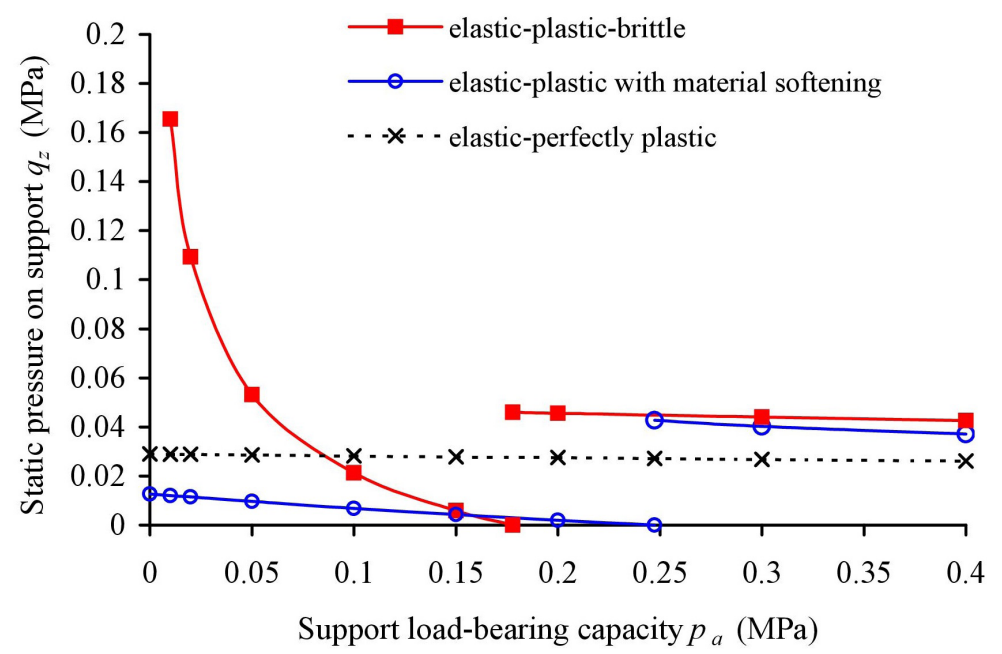

Fig. 10. The course of change in static pressure on the support as a function of the support load capacity

\section{CONCLUSIONS}

Taking into account the strain-softening of the rock medium, after reaching the limit strength, causes a longer distance from the contour of the excavation (deep into the rock mass) to the peak circumferential stress than in the case of omission the softening (elastic-perfectly plastic model). The size of the retraction is a function of geomechanical parameters of the rock, mining parameters (the depth of deposition and dimensions of the excavation) and the support load capacity. The increase in the angle of dilatancy significantly affects the increase of radial displacements of the rock mass within the residual plastic zone. In turn, it has a slight influence on the displacement in the plastic zone with softening and in the elastic zone. The influence of the dilatancy angle on the radial displacement of the mass in the vicinity of the excavation decreases with the increase of the support load capacity.

The obtained quantitative results of the state of stress, displacement and pressure of the rock mass on the support are valid only for the assumed calculation data. They can also be used to quantify the effect of modeling inelastic zones on the state of stress and deformation in the vicinity of the excavation.

Under the given mining and geological conditions, the pressure of the rock mass on the support should be estimated based on the rock medium model that best describes its features.

For the model of the elastic-plastic rock medium with softening, formula for stress $\sigma_{\text {Rrez }}$ was obtained, regardless of the support load capacity. When unevenness occurs, $p_{a} \geq \sigma_{\text {Rrez }}$, a residual plastic zone does not form in the vicinity of the excavation. Then the static pressure of the rock mass on the support is the result of supporting the rocks of the plastic zone on it. If $p_{a}<\sigma_{\text {Rrez }}$, a residual zone is created in the vicinity of the excavation. The rocks in this zone, after detachment and based on the support, exert static pressure on it.

\section{REFERENCES}

1. Alonso E., Alejano L.R., Varas F., Fdez-Manin G. and Carranza-Torres C. Ground response curves for rock masses exhibiting strain-softening behaviour. Int. J. Numer. Anal. Methods Geomech., 2003, 27, 1153-1185.

2. Barla G. Analysis and design methods of tunnels in squeezing rock conditions. Rivista Italiana Di Geotecnica, 2000, 1, 22-29.

3. Berest P., Nguyen-Minh D. and Panet M. Contribution à l'étude de la stabilité d'une cavité soutercai ne dans un milieu avec radoucissement. Rev. Fr. Géotech., 1978, 4, 63-72.

4. Brown E.T., Bray J.W. and Landanyi B. Ground Response Curves for Rock Tunnels. J. Geotech. Eng., 1983, 109 (1), 15-39.

5. Carranza-Torres C. Elasto-plastic solution of tunnel problems using the generalized form of the hoek-brown failure criterion. Int. J. Rock Mech. Min. Sci., 2004, 41 (1), 629-639.

6. Chen L., Mao X., Chen Y. and Liu D. A new unified solution for circular tunnel based on a fourstage constitutive model considering the intermediate principal stress. Adv. Civ. Eng., 2018, 2, 1-14.

7. Design documentation of the mine of Lubelski Węgiel "Bogdanka" S.A. (in Polish), No 4206/17/14/133/KD. Bogdanka (Poland), 2014. 
8. D’Obryn K. and Tajdus A. Geomechanical numerical analysis as a guidance for preservation works of the "Wieliczka" salt mine site. Studia Geotechnica et Mechanica, 2017, 39 (2), 25-34.

9. Fahimifar A. and Ranjbarnia M. Analysis of circular reinforced tunnels by analytical approach. Journal of Structural Engineering and Geotechnics, 2011, 1 (2), 45-55.

10. Hoek E. Rock-support interaction analysis for tunnels in weak rock masses. Tunneling Journal, April/May, 2012, 44-49.

11. Kargar A. and Rahmannejad R. An analytical solution for the ground reaction curve of brittle rocks, including gravity. Arab. J. Geosci., 2015, 8, 1479-1486.

12. Khomenko O., Kononenko M. and Bilegsaikhan J. Classification of Theories about Rock Pressure. Solid State Phenom., 2018, 277, 157-167.

13. Kyung-Ho P., Bituporn T. and Joo-Gong L. A simple procedure for ground response curve of circular tunnel in elastic-strain softening rock masses. Tunn. Undergr. Sp. Tech., 2008, 23, 151-159.

14. Lu Yan-er and Yang Wu. Analytical solutions of stress and displacement in strain softening rock mass around a newly formed cavity. J. Cent. South Univ., 2013, 20, 1397-1404.

15. Marczak H. Application of the elastic-plastic model in the analysis of the displacement in a rock mass. Advances in Science and Technology Research Journal, 2018, 12 (2), 188-196.

16. Mroz Z. and Krucinski S. Elastoplastic analysis of stress and displacement field in the vicinity of circular tunnel with account for degradation effect (in Polish). Arch. Min. Sci., 1984, 29, 205-229.

17. Nguyen P.M.V. and Niedbalski Z. Numerical modeling of open pit (OP) to underground (UG) transition in coal mining. Studia Geotechnica et Mechanica, 2016, 38 (3), 35-48.

18. 18. Oreste P. The convergence-confinement method: roles and limits in modern geomechanical tunnel design. Am. J. Appl. Sci., 2009, 6 (4), 757-771.

19. Polish Committee for Standardization. Underground headings and chambers - Shell type support - Principles of designing and statistic calculations. PN-G-05600:1998P. ICS: 93.060; 73.020; 93.160. Warszawa (Warsaw), 1998.

20. Polish Committee for Standardization. Underground headings and chambers - Vaulted lining Principles of designing and static calculations. PNG-05020:1997P. ICS: 73.020. Warsaw, 1997.

21. Popovici A., Ilinca C. and Anghel C. Assessment concerning the domain of applicability of Protodiakonov method in calculus of underground structures. Mathematical Modelling in Civil Engineering, 2017, 13 (1), 21-31.

22. Purwodihardjo A. and Cambou B. Effect of strainsoftening on settlement due to tunnelling in soft soil, In: Rosenbaum M.S. and Turner A.K. (Eds.), New Paradigms in Subsurface Prediction. Lecture Notes in Earth Sciences, 99, Springer-Verlag, Berlin/Heidelberg, Germany, 2003, 173-188.

23. Rak Z. and Stasica J. Studies of physical and mechanical properties of rocks in the in-situ conditions of the LW Bogdanka mine (in Polish). Unpublished Works. Krakow, 2005.

24. Regulation of the Minister of Energy of November 23,2016 on detailed requirements for the operation of underground mining facilities (in Polish). Dz.U. 2017 poz. 1118 - http://www.dziennikustaw.gov. $\mathrm{pl} / \mathrm{du} / 2017 / 1118 / 1$

25. Ruiz S., Or D. and Schymanski S.J. Soil penetration by earthworms and plant roots-mechanical energetics of bioturbation of compacted soils. PLOS ONE, 2015, 18, 1-26.

26. Saeidi O., Elyasi A., Maleki S. and Fegh A. An analytical closed form solution around undeground openings using different methods. J. Applied Sci., 2012, 12 (5), 440-449.

27. Serafin J.L. and Pereira J.P. Consideration of the geomechanical classification of Bieniawski. Proc. Int. Symp. Eng Geol Underground Construction (Lisbon), 1983, 1(II):33-44.

28. Sharan S.K. Elastic-brittle-plastic analysis of circular openings in Hoek-Brown media. Int. J. Rock Mech. Min. Sci., 2003, 40, 817-824.

29. Wang, Y. Ground response of circular tunnel in poorly consolidated rock. ASCE J. Geotech. Eng., 1996, 122 (9), 703-708.

30. Wichur A. Problems of the design of the longterm excavations' support (in Polish). Górnictwo i Geoinżynieria, 2009, 33 (3/1), 407-436.

31. Xiao Wang, Guo Quan-yuan and Su Yong-hua. Anchorage mechanical effects of tunnel surrounding rock by considering post-peak characteristics. Journal of Highway and Transportation Research and Development (English Edit.), 2017, 11 (1), 49-58.

32. Yang Xiao-li and Huang Fu. Influences of strain softening and seepage on elastic and plastic solutions of circular openings in nonlinear rock masses. J. Cent. South Univ. Technol., 2010, 17, 621-627.

33. Zareifard M.R. and Fahimifar A. A new solution for shallow and deep tunnels by considering the gravitational loads. Acta Geotech. Slov., 2012, 2, 37-49.

34. Zhao Zeng-hui, Wang Wei-ming and Gao Xin. Evolution laws of strength parameters of soft rock at the post-peak considering stiffness degradation. J. Zhejiang Univ-Sci. A (Appl Phys \& Eng), 2014, 15(4), 282-290.

35. Zou Jin-feng, Zuo Song-qing and Xu Yuan. Solution of strain-softening surrounding rock in deep tunnel incorporating 3D Hoek-Brown failure criterion and flow rule. Math. Probl. Eng., 2016, 1-12. Retrieved September 15, 2018, from http://dx.doi. org/10.1155/2016/7947036. 